Article

\title{
Information Transmission Mechanism of Inequality of Opportunity and Effort on Settlement Intention
}

\author{
Junjie Gao $\mathbb{Q}^{\circ}$, Lyubing Feng * and Xianguo Yao \\ School of Public Affairs, Zhejiang University, Hangzhou 310058, China; junjie_gao@zju.edu.cn (J.G.); \\ cec_yaoxg@zju.edu.cn (X.Y.) \\ * Correspondence: 11822034@zju.edu.cn
}

Citation: Gao, J.; Feng, L.; Yao, X.

Information Transmission

Mechanism of Inequality of

Opportunity and Effort on Settlement

Intention. Sustainability 2021, 13, 4566.

https://doi.org/10.3390/su13084566

Academic Editors: Gabriela Topa and Marc A. Rosen

Received: 11 March 2021

Accepted: 18 April 2021

Published: 20 April 2021

Publisher's Note: MDPI stays neutral with regard to jurisdictional claims in published maps and institutional affiliations.

\begin{abstract}
China is promoting sustainable economic development through urbanisation, but migrants' low settlement intention has become an obstacle to the urbanisation process. The key leading to this problem is that the current economic system lacks an index with high information transparency to convey the characteristics of the destination city, so that migrants' choice of settling city is a kind of act of chance. By referring to Roemer's equality of opportunity theory, this paper takes the indexes of inequality of opportunity (IO) and inequality of effort (IE) of the destination as market signals representing the characteristics information of destination, innovatively proposes an information transmission mechanism to improve migrants' settlement intention. According to the IO and IE of the destination, migrants can effectively identify the economic incentive modes and social characteristics of the destination city before migration, and then make an accurate judgment on the possibility of realizing income growth and social integration in the destination. The feasibility of this mechanism was verified by the data of China Labor-force Dynamics Survey (CLDS). The result indicates that IO and IE can indeed convey information about economic incentives of the destination and attract migrants to settle down there. In addition, IE can convey positive messages on two social characteristics of the destination, namely, promotion fairness and social network, while IO sends negative messages on both aspects. Cities that plan to expand their population scale can leverage this mechanism to optimise their IO and IE indexes, so as to attract migrants to settle down in the city.
\end{abstract}

Keywords: settlement intention; inequality of opportunity; inequality of effort; economic incentives; promotion fairness; social network

\section{Introduction}

China's economy is going through a structural shift, where consumption has become an essential engine for economic growth. The urbanisation of the permanent resident population, where China's largest domestic demand potential and development momentum lies, supports implementing the strategy of boosting domestic demand and stabilising economic growth [1]. In recent times the government has committed to urbanising the mobile population. Local governments have taken the initiative in facilitating the settlement of the mobile population through a series of policies such as gradually cancelling restrictions on household registration. However, the signs of 'counter-urbanisation' are also salient as a considerable part of the mobile population has shown less willingness to settle in cities and frequent secondary migration. According to macro data from 2017, China's domestic mobile population was 244 million, accounting for $17.55 \%$ of the total population [2], of which $48.7 \%$ expressed a clear desire to settle [3]. Under such circumstances, although China's permanent urban residents' rate rose to $60.60 \%$ by the end of 2019 [4], the rate is still below the $80 \%$ average of developed countries. Hence, for local governments, it is worth pondering over how to raise migrants' settlement intention, realise the effective long-term agglomeration of migrants in the destination cities and thereby unleash the economic growth potential of population aggregation. 
A closer look at the reasons leading to low settlement intention of migrants reveals a phenomenon that has been ignored by previous studies. The low settlement intention of migrants in China is mainly due to the fact that the migrants show an obvious chance behaviour in the choice of destination city [5,6]. It reflects an important economic problem: for those who have moved to the destination city, the fundamental reason for their low willingness to settle is that the expected settlement utility based on the actual living experience is lower than the one based on the collected information before the migrants move to the destination city. Incomplete information of the destination city causes the expected bias [7]. As a result, the source composition of migrants pouring into the destination city includes a large number of migrants who do not match the characteristics of destination city, so that the overall situation shows a low settlement intention. Therefore, to improve migrants' settlement intention, it is key to use an index with high information transparency of the characteristics of destination city as the market signal, eliminate the misjudgment of migrants' expected settlement utility caused by information asymmetry, and reduce the mismatch between migrants and destination city to achieve accurate migration.

The existing studies have classified the factors affecting settlement decision into two categories: social characteristics [8,9], and economic incentives [10,11]. Unfortunately, there is a serious lack of information in the existing indexes of the two categories, to the point that migrants cannot accurately judge the matching degree between them and the destination city when making settlement decision. Therefore, after immigrating to take a chance, the actual settlement utility perception is likely to be lower than the psychological expected utility. For instance, information like social characteristics of the destination is difficult to be confirmed by individual short-term observation, and before they come to the destination city, migrants can only make a judgment relying on the personal feelings of former migrants [12]. Since the number of individuals who can provide information is limited, such information is not scientific enough to represent the social characteristics of the destination city. In addition, the market signal which usually represents the economic incentives of the destination is the income inequality index. However, this index measures only regional disparities in income levels, but does not indicate which factors migrant possesses are most likely to produce high economic returns in the market of the destination [13]. Migrants cannot identify the settlement income growth mode of the destination city by the single index of income inequality, so that they cannot form an accurate settlement income growth expectation based on their human capital characteristics, and it is easy to create a psychological gap between expectations and actual feelings. Therefore, it is necessary to build an information transmission mechanism, using concise indexes as the corresponding market signals to provide migrant more detailed information about the economic incentive modes and social characteristics of the destination city, so that migrants can make a reasonable match between their own characteristics and the characteristics of the destination city, forming a relatively accurate expected settlement utility, and reducing fluctuations in psychological expectation. This is also the aim of our paper.

To build such an information transmission mechanism, market signal index should meet two features. First, this concise index can reasonably represent the urban characteristics of the destination city; that is, it is obtained by scientific measurement of sufficient sample size; next, this index contains information about the specific methods of economic incentives and the difficulty of social integration at the same time; that is, it presents higher information transparency. Roemer's equality of opportunity theory provides a useful reference for setting up the aforementioned market signals. According to the egalitarianism principle of personal responsibility [14], Roemer [15] divides income determinants into two categories: factors beyond individual control (called 'circumstances') and factors within individual control (called 'effort'). Therefore, the composition of income inequality can be classified into inequality of opportunity (IO) and inequality of efforts (IE). IO stems from 'circumstances' beyond the control of individuals, such as clan, parents' educational background, and family social status, whereas IE sources from controllable differences in individuals' 'efforts', such as working hours and behaviours to learn knowledge and 
skills [16]. This categorises the determinants of income inequality in destination cities, which helps unfold the economic incentives and social characteristics of destination cities, thereby creating a relatively sufficient information condition for migrants to know the destination city and to judge the possibility of their income growth and social integration in the destination city.

As a market signal, IO and IE can directly convey the information of the economic incentive mode. According to Roemer's theory, the possibility of migrants achieving income growth in a destination city depends on their circumstance and effort factors. In regions where IO prevails, income growth depends more on individuals' family background and social class rather than on individual efforts. The higher IO in destination cities, the more chances for individuals with advantages in circumstances endowments to form higher expected incomes via circumstances factors [17], but those with inadequate circumstances endowments have difficulty in increasing their incomes. In addition, IO and IE can indirectly convey information about the social characteristics of the destination city. Excessive IO makes income growth more dependent on innate circumstances factors so that people in the city would question the justice of income growth [18], which is unconducive to attracting migrants. If IE is high, however, individuals incline to pay more effort to earn a higher expected income [15], and it is also very likely that efforts will be the determinant of income growth. So, IE is more as a signal in favor of settlement. As far as the difficulty of social integration is concerned, IE and IO can reflect the social conditions of the region $[18,19]$. Excessive IO segments social networks into various small-scale incomparable circles, but excessive IE motivates people to communicate in the markets and frequently interact with each other, possibly resulting in breaking social barriers [18-21]. Therefore, the indicators of IO and IE can be used as market signals for destination cities, with which migrants can judge whether their own characteristics are in tune with those of the city and form a relatively accurate expected settlement utility before migrating to the destination city.

The contribution of this study is as follows. In order to solve the problem of high mismatching degree between migrants and settled cities under the condition of insufficient information transmission of destination city, the paper creatively constructs an information transmission mechanism that connects the IO and IE indexes and the possibility of settling down in the destination city, providing sufficient information for migrants to choose the destination accurately. This mechanism adopts IO and IE with higher information transparency as the indexes to convey the specific characteristics information of the destination city, which can help migrants accurately judge the possibility of settling down in the destination city, so as to avoid the hit-and-miss migration behaviour. For the destination city, this mechanism can pre-screen the composition of the source of the migrants pouring into the city, to reduce the possibility of mismatched migrants entering by mistake, so as to improve the settlement intention of the actual migrants in the city. This study also fills the knowledge gap on how to solve the mismatch between migrants and destination city due to the lack of information about the destination.

Based on Roemer's equality of opportunity theory, and according to the international general measurement methods [15-17], we calculated the IO and IE indexes of major representative cities in China. By referring to the China Labour-force Dynamic Survey (CLDS) database, we tested the information transmission of the two market indicators for the characteristics of the destination cities, including the feasibility of the impact mechanism on the settlement intention of migrants. The reasons for choosing migrants moving among cities in China as the sample are as follows. First, China has prioritised urbanisation, but cities have different abilities in drawing migrants to settle in. Local governments are concerned with how to use market means to reduce the mismatch between migrants and the destination cities at its source to secure effective population agglomeration. Our research provides a new course for solution. Second, since the reform and opening-up, migrants have been essential contributors to China's economic growth. For many years, migrants have longed to settle in cities where they work and share the development dividends of reforms. In the context of urbanisation in which cities begin to accept migrants, the 
settlement behaviours and life qualities of migrants have always been a matter of great concern for the government. Our mechanism is conductive to elevating settlement intention and happiness. Migrants can effectively screen destination cities with IO and IE indexes. We utilise market signals of IO and IE to solve the long-standing problem of incomplete information on the characteristics of destination cities, avoid the mismatches between migrants and destination cities due to information asymmetry and enable migrants to effectively identify and rationally choose their destinations.

The remaining content is organised as follows: Section 2 elaborates the mechanism of IO and IE on migrants' settlement intention and proposes hypotheses to be tested. Section 3 describes where the data came from, constructs empirical models, and introduces variables and research methods. Section 4 conducts empirical analysis to test the hypotheses. Section 5 discusses the research results. Section 6 concludes and provides policy recommendations.

\section{Literature Review and Research Hypotheses}

\subsection{Unequal Signals of Economic Incentives and Settlement Intention}

The economic incentive mode of the destination city is an intuitive market message conveyed by inequality of opportunity and inequality of effort. The index used to signal economic incentives was regional inequality of income. However, no consistent conclusion was reached on this index's effect on settlement intention, so that many scholars question the importance of income inequality for settlement decision. Lin Yifu et al. [22], Whyte [23] and Tan et al. [24] found that the relative income gap between two regions has a significant positive impact on migration and settlement. However, Zhu et al. [25], Tang et al. [26] and Zhang et al. [27] discovered that the impact of income inequality on settlement was not significant. The reason why the existing research conclusions are controversial is that the information about income inequality does not clearly convey the income growth pattern of the destination city, and even leads to misjudgment when the individual evaluates the settlement utility based on it.

The level of IO and IE of destination city can provide migrants more detailed information about economic incentives, enable them to understand the main sources of income inequality of the destination city and identify specific ways to achieve settlement income growth in the region, so as to form stable expectations about the economic utility of settlement. The city with a high IO index means that the income growth in this city mainly comes from the environmental factors of the migrants, and that migrants' achievements can achieve better inter-generational transmission if they settle down in the city. Dardanoni et al. [28] pointed out that when parents' contributions are also passed on to their children, the offspring can obtain direct material wealth, the benefits of which would continuously increase in value with the aggravation of the opportunity inequality of the living area. Inequality of opportunity provides risk-free benefits to environment owners through high returns to the environment [29]. Marrero and Rodriguez [30] also argued that income growth of individuals and families can benefit from inequality of opportunity in the cities where they settle. Therefore, inequality of opportunity becomes an economic incentive to attract migrants to settle down, attracting those who prefer to maximise the long-term benefits of their families and their children [31].

The city with a high IE index means that the income growth in this city mainly comes from the effort factors of the migrants. For human capital that takes effort as the means to obtain income, its market value will face appreciation [32]. The inequality of effort indicates that the market demand for human capital is not yet saturated. Hardworking individuals with higher human capital can increase their earnings by increasing market transaction frequency and transaction scale [33]. According to human capital theory, settlement decision is a process of maximizing the value of human capital and pursuing the maximisation of economic benefits [34]. Under the condition of given human capital and environmental endowments, inequality of effort can ensure that migrants get relatively generous immediate returns. Therefore, inequality of effort is also an economic incentive to 
attract migrants to settle down, attracting those who prefer short-term economic incentives to maximise the value of their human capital [35]. Based on the above analysis, this paper proposes the first hypothesis to be tested, in order to test the feasibility of the information transmission between the two market signals and settlement intention in terms of the economic incentive mode of the destination.

Hypothesis 1 Both indicators of IO and IE can convey the information of economic incentive modes of destination cities and attract migrants to settle in.

\subsection{Unequal Characteristics, Social Integration, and Settlement Intention}

Settlement is also a process in which migrants gear themselves into society [36]. To a certain extent, the social climate of destination cities is affected by IO and IE, especially the social characteristics of promotion fairness and social network, which are closely linked to economic incentives. These social characteristics would significantly affect the expected utility of settlement [37].

\subsubsection{A Sense of Fairness in Career Promotion and Settlement Intention}

For migrants, a critical basis for determining happiness after moving in is a relatively fair market order in the destination city. In A Theory of Justice, Rawls pioneered the discussion of equitable distribution [38]. He pointed out that the access to 'basic goods' (particularly income and consumption) by the groups with minimum benefit in society is a standard of measuring the overall level of social welfare, thus shifting the focus of 'equality' from distribution results to the analysis of the principle of justice. Cohen [39] further noted that a just society does not necessarily mean that all people are equally happy, similarly rich or receive the same education, but it must grant all members with equal opportunities. Therefore, opportunities rather than achievements are the proper 'currency of equality and justice'. Although public behaviours would not eradicate inequality results, people have been yearning for a fair social atmosphere.

As a social feature closely related to income growth, the perception of fairness in career promotion is affected by the IO and IE in destinations. It enables IO and IE to indirectly convey information about promotion fairness in the social characteristics of the destination city. According to research on promotion fairness, if differences in promotion are caused by external factors (such as gender, race, and age) rather than by individuals' abilities, it is more likely to spark dissatisfaction among employees [40]. Individuals would consciously make a subjective judgement on the prospects of where they live based on past promotion experience and expectations for future promotion and then judge whether they are suitable to live there [41]. According to Roemer's theory, in areas with high IO, income growth depends on uncontrollable circumstances factors, and the reference basis for career promotion is more on individuals' circumstances characteristics than on their efforts [15]. This will undoubtedly affect people's satisfaction with destination cities. In areas with high IE, income growth relies on the level of human capital and diligence of individuals. Career promotion is mainly the result of individuals' competence. This fair atmosphere will also contribute to bolstering the expected utility of settlement. On the basis of these, a second hypothesis is proposed:

Hypothesis 2 The IO and IE in destination cities can indirectly affect migrants' settlement intention through the information of promotion fairness.

\subsubsection{Social Network and Settlement Intention}

Settlement behaviours also have distinct social attributes, whose primary manifestation is a social network [42]. Migrants' settlement decisions involve judging the possibility of establishing effective social relations in destination cities. The settlement, understood as 'a dynamic social process', aids migrants to form a social and cultural attachment to destination cities [43]. By building a sound social network and maintaining frequent 
interactions with locals, migrants can feel at home psychologically [44]. Reyes [45] and Korinek et al. [46] found that a strong social support network in destination cities can positively prompt migrants' settlement intention. In contrast, when the social support network is weak, they are prone to feel socially excluded, and the willingness to settle for a long time becomes less likely [47].

The level of IO and IE in destination cities will indirectly affect the pattern of social relations in the region. In an IO-based income growth model, the income growth is achieved from circumstance. In this way, it is likely to form a small-scale personalisation transaction model so that social relations are concentrated in the mutual support exclusively among members of small groups, which outsiders would find hard to blend into [48]. However, in an IE-based income growth model, individuals' human capital is the main source of income. Hence, the communication and coordination capability of human capital in the society can be released to a large extent, making it easy to set up a relatively open social network in the place [42]. Because of the close relationship between social relations and the settlement utility, owning large effective social connections will end up with higher settlement intention [49]. On the basis of the aforementioned analysis, here is a third hypothesis:

Hypothesis 3 The IO and IE in destination cities can indirectly affect migrants' settlement intention through the information of social networks.

On the basis of the aforementioned analysis, the conceptual model proposed in the theoretical analysis of this paper is shown in Figure 1. This model describes the theoretical mechanism of IO and IE affecting settlement intention; H1 represents the direct impact through economic incentives, whereas $\mathrm{H} 2$ and $\mathrm{H} 3$ represent the indirect impact through social integration. Other factors that affect settlement intention, such as regional and individual factors, are not the focus of this research, so they will only be used as control variables.

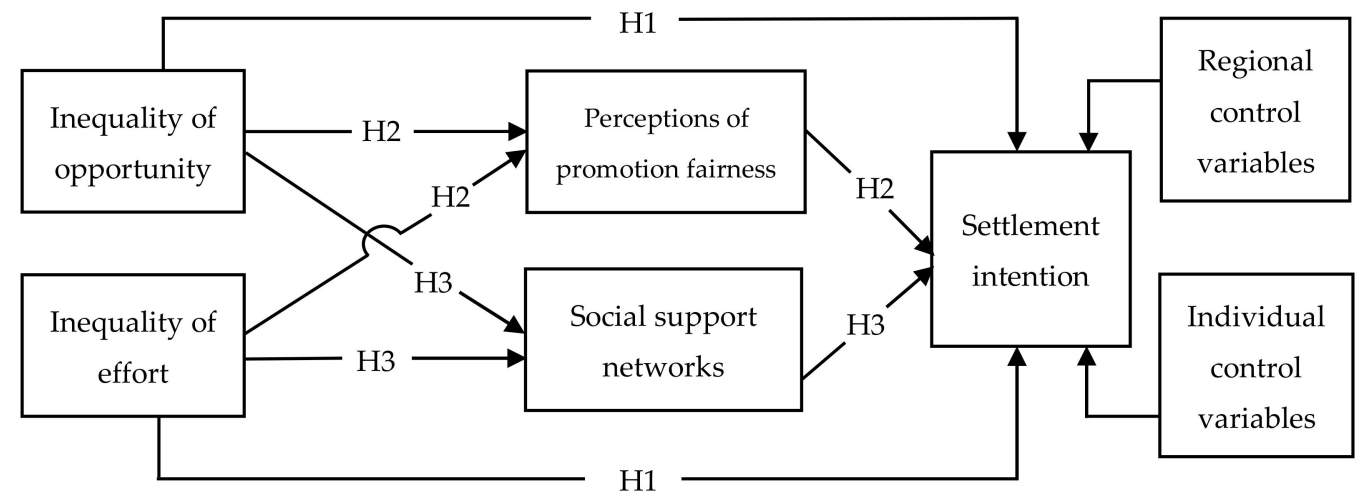

Figure 1. Mechanism of IO and IE influencing settlement intention.

\section{Research Methods}

\subsection{The IO and IE Indexes of Major Representative Cities in China}

This paper is to examine whether there is a correlation between IO and IE indexes and settlement intention. Before conducting metrological regression, it is necessary to measure the IO and IE indexes of representative cities in China with the current standardised measurement methods. Given that the existing research has formed a standard algorithm for the measurement of IO and IE indexes, and the measurement method itself is not the focus of this paper, the paper selects the same variables and the same methods as the existing research to calculate IO and IE Gini coefficients of representative cities in China, to avoid measurement deviations caused by different variables and measurement methods, so as to obtain a general measurement result. This is to ensure that when IO and IE indexes are used to verify the information transmission mechanism, the conclusions obtained are 
more universal. This paper adopts the same parameterised program and the same variables as Almås et al. [14] and Bourguignon et al. [16] to calculate IO and IE Gini coefficients of China's representative cities in 2015. The specific variables and measurement methods will not be detailed here. The data used are micro data from the 2016 China Labor-force Dynamics Survey (CLDS) [50], which come from the comprehensive database of the Centre for Social Survey of Sun Yat-sen University. The survey sample is composed of a total of 21,086 individuals, encompassing cross-sectional data on individual laborers aged between 18 and 65 years. The survey data cover 157 cities in 29 provinces, accounting for $95 \%$ of the country's population.

The survey sample of each city is selected by probability sampling, which is proportional to the size of the workforce in the city, and the sampling results are representative of the city. After eliminating the missing value of the samples, we further eliminated cities with sample size lower than 45 , to ensure that the final sample is representative of the city. Finally, a total of 14,986 samples from 146 cities were used to measure IO and IE Gini indexes, with a mean of 102, the minimum sample size of 47 (Baoshan, a small city in Yunnan province) and the maximum sample size of 351 (Guangzhou, the provincial capital of Guangdong province). The difference in sample size between cities stems from the difference in the labor base of cities of different sizes. Although the sample size of some cities is relatively low, they are still representative of cities. We plot the IO and IE indexes of major representative cities with ArcGIS 10.1.

The IO Gini coefficient of representative cities in China is shown in Figure 2. White represents the unstudied areas, while colored areas show the IO Gini coefficient value of the representative cities. It can be seen from the color distribution that, the IO value is relatively low in cities in western China, especially in urban agglomerations in southwest China, the IO in the Yangtze River Delta urban agglomeration is slightly higher than that in the Pearl River Delta urban agglomeration and is relatively high in the Beijing-Tianjin-Hebei region and the three northeastern provinces. The lowest IO value is found in Meishan, Sichuan Province (0.006), while the highest is in Anshan, Liaoning Province (0.725).

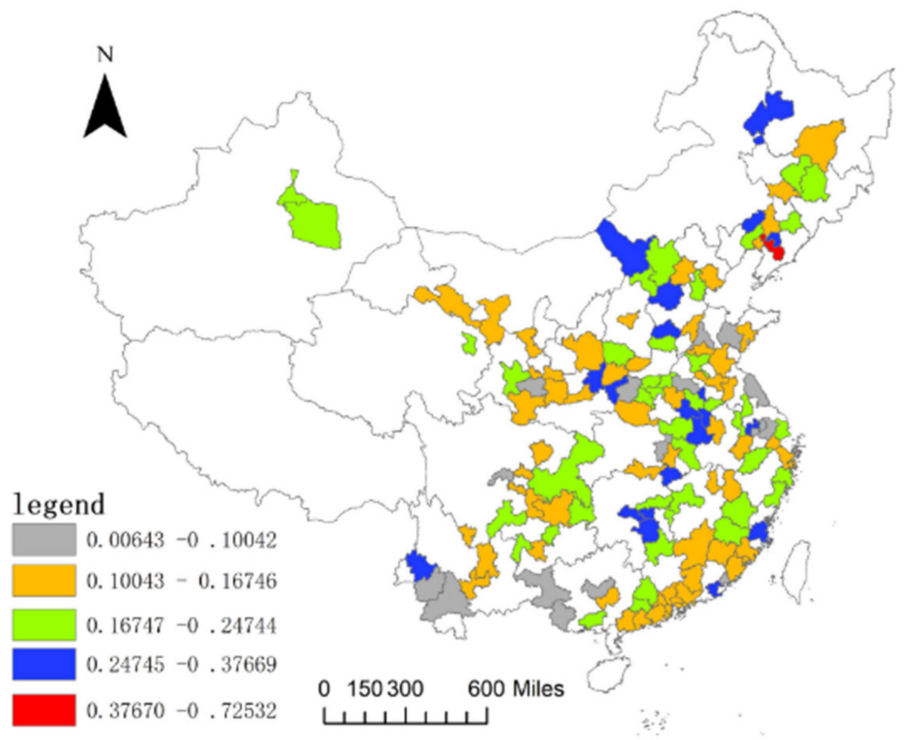

Figure 2. The IO Gini Indexes of Major Representative Cities in China.

Figure 3 shows the IE Gini coefficient of representative cities in China. It can be seen that the IE value is relatively high overall in China, with lots of red and blue cities, but there are obvious differences in different cities. The IE value is relatively low in urban agglomerations in northeast China and northwest China and is generally high in southwest China and eastern and central regions. The value is highest in some of the emerging inland cities, marked prominently in red on the map, which are also the main areas of 
net population outflow in the past but have seen a wave of return in recent years. The IE value in urban agglomerations in the Yangtze River Delta and the Pearl River Delta is at the middle level. The lowest IE value is found in Anshan, Liaoning province (0.147), and the highest in Zhaotong, Yunnan province (0.745).

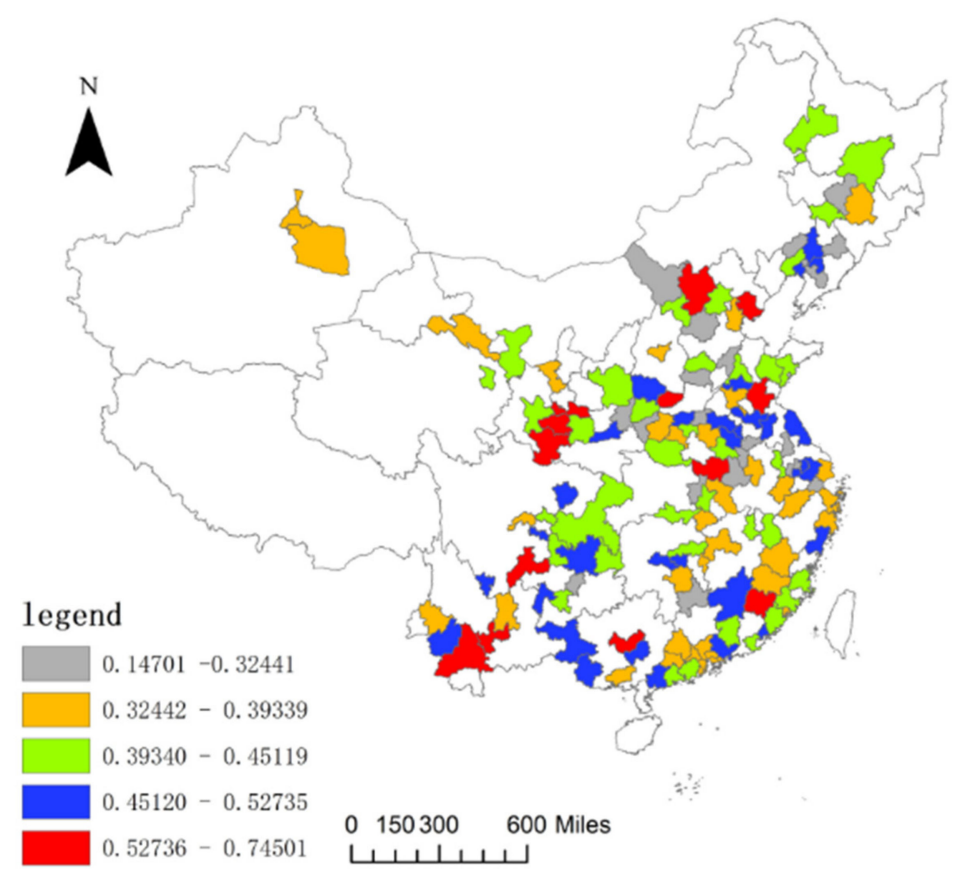

Figure 3. The IE Gini Indexes of Major Representative Cities in China.

The low IO and IE in eastern cities may result from the reform of income marketisation, which has been marketised for 40 years, and a market-oriented income distribution pattern has formed. Therefore, the income created by the circumstances has been restricted, whereas the income created by efforts has been fully released after embracing competitive markets for years. The high IE in western cities may be due to the economic benefits brought by industrialisation. Western cities are in the initial stage of marketisation, serving as the undertaker of industries transferred from the eastern cities. This has greatly stimulated the enthusiasm of workers there, so the IE is high. Nonetheless, the market size of the central and western cities is not as good as the eastern cities, so the competition among market entities for limited profit opportunities is more intense. That is why the income inequality caused by the circumstances is high.

\subsection{Empirical Test of the Information Transmission Mechanism}

In order to test whether IO and IE indexes in the information transmission mechanism proposed in this paper are really the effective indexes by which migrants judge the possibility of settlement, this paper is going to use CLDS data in 2016 to conduct empirical tests on the three hypotheses proposed in the second part. We adopt IO and IE as explanatory variables and migrants' settlement intention as the explained variables. Given that the explained variable, namely, settlement intention, is an ordered discrete structure with five levels of finite sequence, this study chooses an ordered probit model for regression. Because both the IO and IE are mainly affected by the regional income distribution system, they would not change sharply in the short-term. Therefore, it is reasonable to use cross-sectional data to verify the influence mechanism of IO and IE on settlement intention. Referring to the research design formulated by Marrero and Rodríguez [30], the empirical model is constructed as

$$
\text { PSI }_{i, t}=\alpha_{0}+\alpha_{1} \text { inequality }_{i, t-1}+\alpha_{2} \text { indiviual }_{i, t}+\alpha_{3} \text { region }_{i, t}+\varepsilon_{i, t}
$$


where the subscripts $i, t$ and $t-1$ denote individual dimensions and time dimension respectively, and $P S I_{i, t}$ denotes settlement intention, which is represented by five levels. To avoid estimation errors caused by reverse causality, explanatory variables inequality $y_{i, t-1}$ is used to denote the inequality index of the previous year, including both the IO and IE indexes. Existing studies related to the settlement have proved that the individual characteristics of migrants and the social security status of destination cities will affect their settlement intention [51]. Therefore, this study adds indiviual ${ }_{i, t}$ and region ${ }_{i, t}$ as control variables. $\varepsilon_{i, t}$ refers to other stochastic disturbances. The regression results of model (1) can test our hypothesis 1 .

According to $\mathrm{H} 2$ and $\mathrm{H} 3, \mathrm{IO}$ and IE may affect settlement intention by promoting perceptions of fairness and social network. To verify these hypotheses, the following mediation effect model is set up echoing with model (1):

$$
\begin{gathered}
Z_{i, t}=\beta_{0}+\beta_{1} \text { inequality }_{i, t-1}+\beta_{2} \text { indiviual }_{i, t}+\beta_{3} \text { region }_{i, t}+\varepsilon_{i, t} \\
\text { PSI }_{i, t}=\gamma_{0}+\gamma_{1} \text { inequality }_{i, t-1}+\gamma_{2} Z_{i, t}+\gamma_{3} \text { indiviual }_{i, t}+\gamma_{4} \text { region }_{i, t}+\varepsilon_{i, t}
\end{gathered}
$$

On the premise that the coefficients of IO and IE in model (1) are significant, a test is made on models (2) and (3); $Z_{i, t}$ denotes perceptions of promotion fairness or social network variables; if the coefficients of $\beta_{1}$ and $\gamma_{2}$ are significant, the mediation effect is verified as effective. The regression results of model (2) and model (3) can test hypothesis 2 and hypothesis 3 . Specifically, variables are expounded as follows:

(1) Personal settlement intention (PSI): As a subjective decision, PSI is often measured by a natural sequence in the economic sphere. At present, the frequently used method of measuring PSI in labour economics is questionnaires based on large samples, in which PSI is denoted by ordinal numbers in an ordinal scale ranging from 1 to 5 , which corresponds to the degree of the settlement intention ' 1 ' $=$ no settlement intention and ' 5 ' $=$ strong settlement intention. Comparing PSI with IO and IE indexes, it is evident that PSI is positively correlated with the inequality indexes.

(2) Control variables (correspond to indiviual $_{i, t}$ and region $_{i, t}$ in models): Individual control variables (indiviual ${ }_{i, t}$ ) include age $(A G E), A G E^{2}$, gender $(G E N)$, political status $(P O L)$, educational background $(E D U)$, and state-owned enterprise $(S O E)$. According to the life cycle theory, there is a nonlinear relation between age and income, and migrants' settlement intention will change with age [52]. $\mathrm{AGE}^{2}$ is calculated as age $*$ age/100. GEN is coded as $1=$ male and $0=$ female. When marketisation is at a low level, admission to the Communist Party of China (CPC) helps to obtain higher income [53]. POL is coded as $1=$ members of the CPC and $0=$ others. As China's wage system becomes increasingly marketised, the longer they receive education $(E D U)$, the greater the probability of earning high incomes, which would exalt the probability of settlement [54]. State-owned enterprises provide employees with relatively complete institutional benefits to facilitate employees' settlement [55], so it is coded as $1=S O E$ and $0=$ others. Regional control variables $\left(\right.$ region $\left._{i, t}\right)$ include resident basic medical insurance $(B M I)$, new rural cooperative medical scheme (NRCMS), regional pension system (RPS) and social endowment insurance for residents $(S E I)$, as all of them are revenue and medical guarantees provided by government finance for individuals [56]. The variable is coded as $1=$ those who possess social security and $0=$ others.

(3) Mediating variables (correspond to $Z_{i, t}$ in model (2) and model (3)): perceptions of promotion fairness $(P P F)$ can be measured by the question 'How satisfied are you with the fairness of promotion opportunities?' in the questionnaire. This subjective feeling is divided into five levels, with ' 5 ' $=$ highly satisfied and ' 1 ' $=$ highly dissatisfied. Assistance from friends $(A F F)$ is an integral part of the social network. The variable is mainly measured by the number of local friends who deliver assistance and reflects how harmonious the social interaction in destination cities is and the effectiveness of individuals' social networks [57].

(4) Explanatory variables: (correspond to inequality $_{i, t-1}$ in models). Explanatory variables include IO_CITY and IE_CITY. These two variables can be measured by Gini 
coefficient results for 146 representative Chinese cities. Detailed measurement results have been shown in Figures 2 and 3 in Section 3.1.

\subsection{Descriptive Statistical Analysis}

Stata 13.1 is employed to perform descriptive statistical analysis on selected variables (Table 1). It can be seen that the overall IO in China is relatively low, with an average of 0.174 . While the overall IE is relatively high, with an average of 0.425 . The IO and IE indexes of the destination cities show a large degree of dispersion in numerical distribution, indicating that there are obvious differences in different cities. The average value of settlement intention (PSI) is 3.561, indicating that there are more individuals willing to settle. The average PPF is neutral, slightly higher than the average value of 3 , which conforms to relevant statistical laws. The standard deviation of AFF is high, but its average is comparatively low, indicating that most people have a limited number of supportive friends, which is also in line with reality. The mean value of age variable is 44.825 , indicating that the majority of Chinese migrants are middle and young people. The mean value of the gender variable is 0.465 , indicating that the ratio of men and women in the migrant group is basically equal. The average EDU is 9.724, and its standard deviation is 3.973 . This indicates that many people in China are not well-educated, so their income level is relatively low. The mean value of party member variable (POL) is only 0.079 , and SOEs employee variable is only 0.114 , indicating that most of the migrants are non-party workers outside the institutional system, and only a small number of migrants can enjoy the benefits of the system. In terms of social security status, the average BMI, NRCMS, and SEI are low, illustrating that the penetration rate of social security is still low. The average NRCMS is high, implying that most people in the sample are from rural areas.

Table 1. Descriptive statistics of variables.

\begin{tabular}{cccccc}
\hline Variable & $\mathbf{N}$ & Mean & Std. Dev. & Min & Max \\
\hline IO_CITY & 18,660 & 0.174 & 0.067 & 0.006 & 0.725 \\
IE_CITY & 18,660 & 0.425 & 0.078 & 0.147 & 0.745 \\
PSI & 2531 & 3.561 & 1.513 & 1 & 5 \\
PPF & 9118 & 3.041 & 0.935 & 1 & 5 \\
AFF & 19,113 & 10.858 & 36.613 & 0 & 1000 \\
AGE & 19,113 & 44.825 & 12.791 & 18 & 65 \\
AGE & 19,113 & 21.729 & 11.005 & 3.24 & 42.25 \\
GEN & 19,113 & 0.465 & 0.499 & 0 & 1 \\
EDU & 19,091 & 9.724 & 3.973 & 0 & 24 \\
POL & 18,283 & 0.079 & 0.269 & 0 & 1 \\
SOE & 19,113 & 0.114 & 0.317 & 0 & 1 \\
BMI & 18,806 & 0.141 & 0.348 & 0 & 1 \\
NRCMS & 18,820 & 0.618 & 0.486 & 0 & 1 \\
RPS & 18,889 & 0.113 & 0.316 & 0 & 1 \\
SEI & 18,814 & 0.088 & 0.284 & 0 & 1 \\
\hline
\end{tabular}

\section{Results Analysis}

\subsection{Basic Regression Analysis}

Table 2 presents the regression results of the empirical model (1). By gradually adding control variables, when the significance level is $1 \%$, IO and IE significantly increase the settlement intention. This result verifies $\mathrm{H} 1$. The regression results of other control variables are congruent with the expectations set before. The influence of age on settlement intention shows a U-shaped change. Well-educated workers tend to settle down. SOE employees are willing to settle down for a long time, but the influence coefficient of the Party membership is not significant. Regional pensions and health security contribute to settlement intention. BMI, RPS, and SEI bolster settlement intention, whereas NRCMS hinders it. 
Table 2. Model regression results of the impact of IO and IE on settlement intention.

\begin{tabular}{|c|c|c|c|}
\hline \multirow{2}{*}{ Variable } & (1) Oprobit & (2) Oprobit & (3) Oprobit \\
\hline & PSI & PSI & PSI \\
\hline IO_CITY & $\begin{array}{c}3.457^{* * * *} \\
(8.56)\end{array}$ & $\begin{array}{c}3.006^{* * *} \\
(7.22)\end{array}$ & $\begin{array}{c}3.033 * * * \\
(7.16)\end{array}$ \\
\hline IE_CITY & $\begin{array}{c}3.258^{* * *} \\
(8.08)\end{array}$ & $\begin{array}{c}2.637^{* * * *} \\
(6.32)\end{array}$ & $\begin{array}{c}2.866^{* * *} \\
(6.63)\end{array}$ \\
\hline AGE & & $\begin{array}{c}-0.033^{* *} \\
(-2.58)\end{array}$ & $\begin{array}{c}-0.031^{* *} \\
(-2.30)\end{array}$ \\
\hline $\mathrm{AGE}^{2}$ & & $\begin{array}{c}0.062^{* * *} \\
(3.91)\end{array}$ & $\begin{array}{c}0.054^{* * *} \\
(3.24)\end{array}$ \\
\hline GEN & & $\begin{array}{c}-0.298^{* * *} \\
(-6.33)\end{array}$ & $\begin{array}{c}-0.287^{* * *} \\
(-5.90)\end{array}$ \\
\hline EDU & & $\begin{array}{c}0.061^{* * *} \\
(8.08)\end{array}$ & $\begin{array}{c}0.036^{* * *} \\
(4.41)\end{array}$ \\
\hline POL & & $\begin{array}{c}0.205^{* *} \\
(2.23)\end{array}$ & $\begin{array}{l}0.126 \\
(1.30)\end{array}$ \\
\hline SOE & & $\begin{array}{c}0.444^{* * *} \\
(5.96)\end{array}$ & $\begin{array}{c}0.213^{* *} \\
(2.58)\end{array}$ \\
\hline BMI & & & $\begin{array}{c}0.158^{* *} \\
(2.14)\end{array}$ \\
\hline NRCMS & & & $\begin{array}{c}-0.326^{* * *} \\
(-6.17)\end{array}$ \\
\hline RPS & & & $\begin{array}{c}0.448^{* * *} \\
(5.19)\end{array}$ \\
\hline SEI & & & $\begin{array}{c}0.331^{* * *} \\
(3.55)\end{array}$ \\
\hline $\mathrm{N}$ & 2478 & 2364 & 2236 \\
\hline Pseudo $\mathrm{R}^{2}$ & 0.0165 & 0.0506 & 0.0702 \\
\hline
\end{tabular}

p-values in parentheses; Note: ${ }^{*} p<0.05,{ }^{* *} p<0.01,{ }^{* * *} p<0.001$.

\subsection{Machinability Analysis}

The regression results of model (2) are displayed in Table 3. Because all the mediating variables are ordered, an ordered probit model is adopted to estimate them. The results imply that the influence of IO and IE on the mediating variables is in the opposite direction. IO significantly reduces employees' PPF and hinders the expansion of social relations, whereas IE does the opposite.

Table 3. Model regression results of the impact of IO and IE on mediating variables.

\begin{tabular}{ccccc}
\hline \multirow{2}{*}{ Variable } & (1) Oprobit & (2) Oprobit & (3) Oprobit & (4) Oprobit \\
\cline { 2 - 5 } & PPF & PPF & AFF & AFF \\
\hline \multirow{2}{*}{ IO_CITY } & $-0.260^{* *}$ & $-0.194^{*}$ & $-1.024^{* * *}$ & $-0.937^{* * *}$ \\
& $(-2.25)$ & $(-1.75)$ & $(-8.83)$ & $(-7.75)$ \\
IE_CITY & $0.516^{* * *}$ & $0.697^{* * *}$ & -0.065 & $0.207^{*}$ \\
individual & $(2.94)$ & $(3.68)$ & $(-0.58)$ & $(1.73)$ \\
regional & NO & YES & NO & YES \\
N & NO & YES & NO & YES \\
Pseudo R & 8878 & 8136 & 18,394 & 17,012 \\
\hline$p$-values in parentheses; Note: ${ }^{*} p<0.05^{* *} p<0.01^{* * *} p<0.001$. & & 0.0055 \\
\hline
\end{tabular}

The regression results of model (3) are shown in Table 4. To avoid estimation errors of the model resulting from variables' missing, column (3) considers all mediating variables and inequality indicators. The results suggest that when the significance level is $1 \%, \mathrm{IO}$ and IE still have a significant positive impact on settlement intention. Under the conditions of IO and IE, the influence of PPF on PSI is significant when the significance level is 10\%, whereas AFF is significant at $5 \%$, indicating that indirect mechanisms do exist. This verifies 
$\mathrm{H} 2$ and H3. Combining the results in Tables 3 and 4, it can be inferred that IO and IE will have opposite social impacts in destination cities. That is how the settlement decision is transformed into weighing how difficult it is for migrants to integrate.

Table 4. Model regression results of the impact of mediating variables on PSI.

\begin{tabular}{cccc}
\hline & (1) Oprobit & (2) Oprobit & (3) Oprobit \\
\cline { 2 - 4 } Variable & PSI & PSI & PSI \\
\hline IO_CITY & $3.224^{* * *}$ & $3.310^{* * *}$ & $3.249^{* * *}$ \\
& $(6.00)$ & $(8.04)$ & $(6.04)$ \\
IE_CITY & $3.010^{* * *}$ & $3.388^{* * *}$ & $\left(8.836^{* * *}\right.$ \\
PPF & $(5.61)$ & $(5.10)$ & $0.060^{*}$ \\
& $0.070^{* *}$ & & $(1.81)$ \\
AFF & $(2.10)$ & $0.010 * * *$ & $0.0044^{* *}$ \\
individual & & $(2.66)$ & $(2.22)$ \\
regional & YES & YES & YES \\
N & YES & YES & YES \\
Pseudo R ${ }^{2}$ & 0.0651 & 2341 & 1425
\end{tabular}

Based on the results above, we found that IO and IE can effectively transmit information on the economic incentives of the destinations, the fairness of social atmosphere, and the strength of social relations. The transmission of these information helps increase the matching degree between immigrants and destination cities. As pointed out by David MC et al., market information regarding the settlement in a destination city, such as income and prices, are reference indicators for immigrants to learn about the characteristics of the destination city and estimate the expected utility of settlement [58]. In the market structure of the destination city, the information on ways of earning income has always been at a low level of transparency, and information asymmetry has led to the misjudgment of expected income growth to immigrants [59], and increased the risk for immigrants to choose a destination city $[60,61]$. The effective transmission of information about economic incentives in destination cities exhibited by IO and IE enables immigrants to estimate the matching degree between their human capital characteristics and job market demands of destination cities [62,63]. In addition, Agadjanian et al. pointed out that the network complexity of social relations makes it hard for immigrants to effectively understand the characteristics of urban social relations in a short time, but it is a key factor that influences the settlement happiness of immigrants [64]. The lack of information about social characteristics will increase the risk of migratory behaviour and add a sunk cost to the settlement of immigrants $[65,66]$. However, our empirical results reveal that IO and IE can effectively transmit information on the social characteristics of destination cities, helping immigrants make the right choice among destination cities.

As shown in Table 3, IO coefficients in the columns 2 and 4 show degrees of social characteristics information of the destination city. When the IO coefficient of the immigrant area is changed by $1 \%$, it will indicate variations in the $0.194 \%$ of the fairness of the promotion process, and in the $0.937 \%$ of social relationship strength. Apparently, information with regards to social relationship strength is more likely to be demonstrated via IO index since inequality of opportunity is mostly formed with the method of establishing interpersonal relationships [67]. In that case, $19.4 \%$ of the information on the fairness of social atmosphere and $93.7 \%$ of the information on social relationship strength in the city where the immigrant area is located can be delivered to immigrants through IO index. Based on this, immigrants can lower the uncertainty of selecting the destination city in accordance with the IO degree of the city. In addition, based on calculation results of coefficients in the column 2 of Table 3 and the column 3 of Table 4, immigrants can reduce the possibility of mismatch resulted from insufficient information on the fairness of social atmosphere of the 
city by $3.7 \%$ as per variations of $1 \%$ in $\mathrm{IO}$ indexes of the destination city. Moreover, based on calculation results of coefficients in the column 4 of Table 3 and the column 3 of Table 4 , immigrants can reduce the possibility of mismatch caused by deficient information on the fairness of social atmosphere of the city by $1.22 \%$ as per variations of $1 \%$ in IO indexes of the destination city.

IE coefficients in Table 3 also reveal degrees of social characteristics information of the destination city. When the IE coefficient of the immigrant area is changed by $1 \%$, it will indicate variations in the $0.697 \%$ of the fairness of the promotion process as well as in the $0.207 \%$ of social relationship strength. Apparently, information with regards to the fairness of promotion process tends to be demonstrated via IE index since inequality of effort is mainly formed with the market adjustment mechanism [68]. In that case, $69.7 \%$ of the information on the fairness of social atmosphere and $20.7 \%$ of the information on social relationship strength in the destination city can be delivered to immigrants through IE index. Based on this, immigrants can lower the uncertainty of selecting the destination city in accordance with the IE degree of the destination city. In addition, based on calculation results of coefficients in the column 2 of Table 3 and the column 3 of Table 4, immigrants can reduce the possibility of mismatch resulted from insufficient information on the fairness of social atmosphere of the city by $11.8 \%$ as per variations of $1 \%$ in IE indexes of the destination city. Moreover, based on calculation results of coefficients in the column 4 of Table 3 and the column 3 of Table 4, immigrants can reduce the possibility of mismatch caused by deficient information on the fairness of social atmosphere of the city by $0.23 \%$ as per variations of $1 \%$ in IE indexes of the destination city.

\section{Discussion}

The regression results in Table 2 show that IO and IE can significantly promote migrants' settlement intention. Contrary to conventional thoughts, IO has not negatively affected migrants' settlement decisions in terms of income growth expectations. Instead, the message of income growth pattern conveyed by IO is an economic incentive approach to attract migrants to settle down. This means that countless migrants hope to achieve long-term family income growth through risk-free returns. High IO transmits a market sign to migrants that destination cities can securely protect property rights so that they can establish the circumstances endowment for their offspring with considerable market benefits. As a result, migrants form a stable expectation for the income growth of their entire family in such destination cities. High IE, however, signals the scarcity of human capital in, hence addressing their concerns about the volatility of income growth due to risks. Both types of information can effectively arouse migrants' settlement intention. That aside, everyone has a unique preference for risk-free returns, so the coefficient of IO is slightly higher than that of IE.

The indirect mechanism of the influence of IO and IE on settlement intention is primarily realised by influencing PPF and social networks. The test results of the mediation effect in Tables 3 and 4 demonstrate that IE elevates settlement intention by promoting PPF and social network, whereas IO curbs settlement intention by hindering PPF and social network. This coincides with traditional intuition. PPF and social network are both inevitable social factors when migrants settle. As a social feature related to income growth, PPF crystallises the expectations of migrants on their prospects, whether they are positive or negative [69]. Reviewing the general opinions and research results of existing academic literature, there is a positive correlation between social equity and life satisfaction [70]. Fair and reasonable promotion can significantly increase employees' social satisfaction, whereas unfair promotion behaviour may greatly lower their evaluation [71]. The social network is also a necessary condition for migrants to form effective social communication. The number of supportive friends reflects how well they integrate into society and develop themselves in the destination cities. This can help migrants transform their identities and gear into the local society. High IE indicates a fair social atmosphere, where migrants can 
establish an effective social network through hard work. High IO reminds migrants that it is difficult to integrate into a destination society.

The results of other control variables also tally with economic common sense. The influence coefficient of age on migrants' settlement intention is negative, whereas that of $A G E^{2}$ is positive. Young migrants have strong ambitions and motivation to push for better lives and hold higher expectations for future income. Elderly migrants already have enough material wealth to afford settlement expenses. Therefore, the settlement intention of both young and elderly migrants is high. Middle-aged migrants have children to raise, so their main purpose is to acquire short-term benefits rather than having a long-term settlement plan. The influence of state-owned enterprises on settlement intention is positive. That is because, in China, state-owned enterprises and government departments render substantial benefits to staff to ease the pressure of living costs. The influence of being party members is not significant, indicating that the income growth channels of Chinese society mainly rely on market transactions rather than on institutional benefits. Education level promotes settlement intention, as well-educated workers, with a higher stock of human capital to cope with the pressure of market competition, are prone to obtain high incomes. The influence of gender is negative; men migrate out of economic motivations, whereas women are more willing to settle out of family considerations, leading to a more significant population distribution effect than men's migration [72]. Moreover, the basic medical insurance, units' endowment insurance and social endowment insurance for urban residents in destination cities can provide individuals with a guarantee for their income and health.

\section{Conclusions}

In the advancement of urbanisation, the Chinese government has been committed to continuously optimise the market mechanism and rely more on market forces to adjust settlement locations. A critical reason for current migrants' low settlement intention is that they are not sufficiently informed of the income growth mode and on how to integrate into the society of destination cities. Income inequality indicators, which originally served as a market signal, only convey the overall income level of destination cities. The inadequate information causes many migrants to swarm into cities without knowing whether their own characteristics match with the features of the market and society. Only after spending several years in the destination cities do they realise how difficult it is to gain higher income and integrate. This kind of mismatch between migrants and destination cities due to incomplete information hinders China's urbanisation and path of sustainable development.

This paper, by referring to Roemer's equality of opportunity theory, decomposed the income inequality index of destination cities into IO and IE indexes and conducted an empirical test on the signal mechanism of IO and IE affecting settlement intention by extracting data from the CLDS. The results indicate that IO and IE can transmit information about the economic incentive modes and social characteristics of destination cities. By interpreting the indicators of IO and IE in destination cities, migrants can swiftly identify the market and social characteristics. This can mitigate the uncertainty in settlement decisions, and migration behaviours will change from 'taking a chance' to targeted selections.

In the current theoretical circles, administrative measures such as the household registration system, equalisation of public services and citizenship treatment have been regarded as universal approaches to manage the urbanisation of migrants. However, the analytical conclusions of market regulation methods from the perspective of income rarely have clear and operable countermeasures. This study supplemented the market adjustment of migrants' settlement. When government departments release regional income inequality indicators, they should also announce the IE and IO indices. Through these two informative market indicators, hidden information about the income growth pattern and the way to build social relations beneath the surface of income inequality is more transparent. Such improvement in settlement intention driven by information disclosure will also give an impetus to China's urbanisation at the macro level. 
This study also has limitations. There are many ways for IO and IE to affect the settlement intention, but restricted by the availability of data, this study only analysed from the perspective of promoting fairness and mutual assistance in society. In the future when individual tracking data of places of emigration and destination can be obtained, we will carry out further research to measure how much the impact of network information diffusion can change the mismatch between migrants and destination cities. In addition, due to the limited availability of data dimensions, this paper only investigates the influence of IO and IE indexes on transmission capacity of the macro-characteristic information of the destination city. Of course, if individual occupation information is available in the future, we can further test the human capital transfer effect of migrants in the process of career transition between regions and combined with the influence mechanism of information diffusion in destination city of this paper, migrants will be able to judge more precisely how well they are matched with new jobs in their new destinations, which will be an interesting direction for future research.

Author Contributions: Writing-original draft, X.Y., J.G. and L.F.; Writing-review and editing, J.G. and L.F. All of the authors have contributed to the idea of this paper. All authors have read and agreed to the published version of the manuscript.

Funding: This research was funded by the Key Program of the National Natural Science Foundation of China (Grant No. 72034006).

Institutional Review Board Statement: Not applicable.

Informed Consent Statement: Not applicable.

Data Availability Statement: Not applicable.

Conflicts of Interest: The authors declare no conflict of interest.

\section{References}

1. Zhou, C.; Li, M.; Zhang, G.; Wang, Y.; Liu, S. Heterogeneity of internal migrant household consumption in host cities: A comparison of skilled migrants and labor migrants in china. Sustainability 2020, 12, 7650. [CrossRef]

2. Yang, G.; Zhou, C.; Jin, W. Integration of migrant workers: Differentiation among three rural migrant enclaves in Shenzhen. Cities 2020, 96, 1-13. [CrossRef]

3. China Migrants Dynamic Survey in 2018. Available online: http:/ /www.geodata.cn/wjw/\#/home (accessed on 20 May 2020).

4. China's Statistical Bulletin on National Economic and Social Development. 2019. Available online: http://www.stats.gov.cn/tjsj/ zxfb /202002/t20200228_1728913.html (accessed on 28 February 2020).

5. Yang, R.; Xu, Q.; Long, H. Spatial distribution characteristics and optimized reconstruction analysis of China's rural settlements during the process of rapid urbanisation. J. Rural Stud. 2016, 47, 413-424. [CrossRef]

6. Man, P.K.; Fong, E. Momentum of Chinese migration scholarship in East and Southeast Asia. Asian Popul. Stud. 2021, 13, 1-4.

7. Sun, Y.F.; Pan, K.F.; He, Z.L. Intercity migration behavior of Chinese graduates: From home region to work destination. Ann. Reg. Sci. 2020, 64, 111-132. [CrossRef]

8. Massey, D.S.; Akresh, I.R. Immigrant intentions and mobility in a global economy: The attitudes and behavior of recently arrived US immigrants. Soc. Sci. Quart. 2006, 87, 954-971. [CrossRef]

9. Cheng, Z.; Wang, H. Do neighbourhoods have effects on wages? A study of migrant workers in urban China. Habitat Int. 2013, 38, 222-231. [CrossRef]

10. $\mathrm{Hu}, \mathrm{F} . ; \mathrm{Xu}, \mathrm{Z} . ;$ Chen, Y. Circular migration, or permanent stay? Evidence from China's rural-urban migration. China Econ. Rev. 2011, 22, 64-74. [CrossRef]

11. Huang, Y.; Cheng, Z. Why are migrants not participating in welfare programs? Evidence from Shanghai, China. Asian Pac. Migr. J. 2014, 23, 183-210. [CrossRef]

12. Wang, H.; Guo, F.; Cheng, Z. Discrimination in migrant workers' welfare entitlements and benefits in urban labour market: Findings from a four-city study in China. Popul. Space Place 2015, 21, 124-139. [CrossRef]

13. Checchi, D.; Peragine, V. Inequality of opportunity in Italy. J. Econ. Inequal. 2010, 8, 429-450. [CrossRef]

14. Almås, I.; Cappelen, A.W.; Lind, J.T.; Sørensen, E.Ø.; Tungodden, B. Measuring unfair (in)equality. J. Public Econ. 2011, 95, 488-499. [CrossRef]

15. Roemer, J. Equality of Opportunity; Harvard University Press: Cambridge, MA, USA, 1998.

16. Bourguignon, F.; Ferreira, F.H.; Menendez, M. Inequality of opportunity in Brazil. Rev. Income Wealth 2007, 53, 585-618. [CrossRef]

17. Ferreira, F.H.G.; Gignoux, J. The measurement of inequality of opportunity: Theory and an application to Latin America. Rev. Income Wealth 2011, 57, 622-657. [CrossRef] 
18. Alesina, A.; Giuliano, P. Preferences for redistribution. In Handbook of Social Economics; Benhabib, J., Jackson, M., Bisin, A., Eds.; North-Holland Publishing Company: Amsterdam, The Netherlands, 2011; pp. 93-131.

19. Meng, X.; Xue, S. Social networks and mental health outcomes: Chinese rural-urban migrant experience. J. Popul. Econ. 2020, 33, 155-195. [CrossRef]

20. Zhou, Y.; Song, L. Income inequality in China: Causes and policy responses. China Econ. Rev. 2016, 9, 186-208. [CrossRef]

21. Fields, G.; Song, Y. Modeling migration barriers in a two-sector framework: A welfare analysis of the hukou reform in China. Econ. Model. 2020, 84, 293-301. [CrossRef]

22. Lin, Y.J.; Wang, G.W.; Zhao, Y.H. Regional Inequality and Labor Transfers in China. Econ. Dev. Cult. Change 2004, 52, 587-603. [CrossRef]

23. Whyte, M.K. One Country, Two Societies: Rural-Urban Inequality in Contemporary China; Harvard University Press: Cambridge, MA, USA, 2010; Volume 16.

24. Tan, S.; Li, Y.; Song, Y. Influence factors on settlement intention for floating population in urban area: A China study. Qual. Quant. 2017, 51, 1-30. [CrossRef]

25. Zhu, Y.; Lin, L. The continuity and change in the urban settlement intention between the two generation migrants-Based on a survey in Fujian Province. Hum. Geogr. 2012, 27, 1-6.

26. Tang, S.; Feng, J. Understanding the settlement intentions of the floating population in the cities of Jiangsu Province, China. Asian Pac. Migr. J. 2012, 21, 509-532. [CrossRef]

27. Zhang, J.; Huang, J.; Wang, J. Return migration and Hukou registration constraints in Chinese cities. China Econ. Rev. 2020, 63, 101498. [CrossRef]

28. Dardanoni, V.; Fields, S.; Roemer, J.; Sanchez, P. How demanding should equality of opportunity be, and how much have we achieved? In Mobility and Inequality: Frontiers of Research from Sociology and Economics; Morgan, S., Grusky, D., Fields, G., Eds.; Stanford University Press: Palo Alto, CA, USA, 2006; pp. 59-82.

29. Ferreira, F.; Lakner, C.; Lugo, M.; Özler, B. Inequality of Opportunity and Economic Growth: How Much Can Cross-Country Regressions Really Tell Us? Rev. Income Wealth 2018, 64, 800-827. [CrossRef]

30. Marrero, G.A.; Rodríguez, J.G. Inequality of Opportunity and Growth. J. Dev. Econ. 2013, 104, 107-122. [CrossRef]

31. Liu, Y.; Deng, W.; Song, X. Influence factor analysis of migrants' settlement intention: Considering the characteristic of city. Appl. Geogr. 2018, 96, 130-140. [CrossRef]

32. Mejía, D.; St-Pierre, M. Unequal Opportunities and Human Capital Formation. J. Dev. Econ. 2008, 86, 395-413. [CrossRef]

33. Zhang, Y.; Eriksson, T. Inequality of opportunity and income inequality in nine Chinese provinces, 1989-2006. China Econ. Rev. 2010, 21, 607-616. [CrossRef]

34. Jensen, P.; Pedersen, P.J. To stay or not to stay? Out-migration of immigrants from Denmark. Int. Migr. 2007, 45, 87-113. [CrossRef]

35. Tang, S.; Feng, J. Cohort differences in the urban settlement intentions of rural migrants: A case study in Jiangsu province, China. Habitat Int. 2015, 49, 357-365. [CrossRef]

36. Chen, S.W.; Liu, Z.L. What determines the settlement intention of rural migrants in china? Economic incentives versus sociocultural conditions. Habitat Int. 2016, 58, 42-50. [CrossRef]

37. Liu, Y.; Shen, J. Jobs or amenities? Local choices of interprovincial skilled migrants in China, 2000-2005. Popul. Space Place 2014, 20, 592-605. [CrossRef]

38. Rawls, J. A Theory of Justice; Harvard University Press: Cambridge, MA, USA, 1971.

39. Cohen, G. On the Currency of Egalitarian Justice. Ethics 1989, 99, 906-944. [CrossRef]

40. Lemons, A.; Jones, A. Procedural justice in promotion decisions: Using perceptions of fairness to build employee commitment. J. Manag. Psychol. 2001, 16, 268-281. [CrossRef]

41. Kaplan, M.; Ferris, G. Fairness Perceptions of Employee Promotion Systems: A Two-Study Investigation of Antecedents and Mediators. J. Appl. Soc. Psychol. 2001, 31, 1204-1222. [CrossRef]

42. Wu, F.; Logan, J. Do rural migrants 'float' in urban China? Neighbouring and neighbourhood sentiment in Beijing. Urban Stud. 2015, 53, 2973-2990. [CrossRef]

43. Liu, Z.; Wang, Y.; Tao, R. Social Capital and Migrant Housing Experiences in Urban China: A Structural Equation Model Analysis. Hous. Stud. 2013, 28, 1155-1174. [CrossRef]

44. De Vroome, T.; Van Tubergen, F. Settlement intentions of recently arrived immigrants and refugees in The Netherlands. J. Immigr. Refug. Stud. 2014, 12, 47-66. [CrossRef]

45. Reyes, B. Immigrant trip duration: The case of immigrants from Western Mexico. Int. Migr. Rev. 2001, 35, 1185-1204. [CrossRef]

46. Korinek, K.; Entwisle, B.; Jampaklay, A. Through thick and thin: Layers of social ties and urban settlement among Thai migrants. Am. Sociol. Rev. 2005, 70, 779-800. [CrossRef]

47. Haug, S. Migration networks and migration decision-making. J. Ethn. Migr. Stud. 2008, 34, 585-605. [CrossRef]

48. Wang, W.W.; Fan, C.C. Migrant workers' integration in urban China: Experiences in employment, social adaptation, and self-identity. Eurasian Geogr. Econ. 2012, 53, 731-749. [CrossRef]

49. Liu, Z. Supporting or dragging? Effects of neighbourhood social ties on social integration of rural-to-urban migrants in China. Hous. Stud. 2019, 34, 1404-1421. [CrossRef]

50. China Labor-Force Dynamics Survey. Available online: http://css.sysu.edu.cn/Data (accessed on 20 December 2019 ). 
51. Huang, Y.; Liu, W.; Zhuo, Y. Social insurance participation and urban settlement intentions of China's floating population. Popul. Space Place 2020, 3, e2366. [CrossRef]

52. Zhu, Y.; Chen, W.Z. The settlement intention of China's floating population in the cities: Recent changes and multifaceted individual-level determinants. Popul. Space Place 2010, 16, 253-267. [CrossRef]

53. Huang, Y.; Guo, F.; Cheng, Z. Market Mechanisms and Migrants' Settlement Intention in Urban China. Asian Popul. Stud. 2018, 14, 22-42. [CrossRef]

54. Lang, K.; Manove, M. Education and Labor Market Discrimination. Am. Econ. Rev. 2011, 101, 1467-1496. [CrossRef]

55. Zhang, M.; Rasiah, R. Institutional change and state-owned enterprises in China's urban housing market. Habitat Int. 2014, 41, 58-68. [CrossRef]

56. Yue, Z.; Li, S.; Feldman, M.; Du, H. Floating choices: A generational perspective on intentions of rural-urban migrants in China. Environ. Plann. A 2010, 42, 545-562. [CrossRef]

57. Fan, C.C.; Sun, M.; Zheng, S. Migration and split households: A comparison of sole, couple, and family migrants in Beijing, China. Environ. Plann. A 2011, 43, 2164-2185. [CrossRef]

58. David, M.K.; Steven, S.; John, G. How important is selection? Experimental versus non-experimental measures of the income gains from migration. J. Eur. Econ. Assoc. 2011, 4, 913-945.

59. Greenwood, M.J.; Hunt, G.L.; Mcdowell, J.M. Migration and employment change: Empirical evidence on the spatial and temporal dimensions of the linkage. J. Reg. Sci. 2010, 26, 223-234. [CrossRef]

60. Akgü, M.; Liu, X.; Tani, M. Risk Attitudes and Migration. China Econ. Rev. 2016, 37, 166-176. [CrossRef]

61. Manning, C.; Sidorenko, A. The regulation of professional migration in ASEAN. World Econ. 2010, 30, 1084-1113. [CrossRef]

62. Zabel, J.E. Migration, housing market, and labor market responses to employment shocks. J. Urban Econ. 2012, 72, 267-284. [CrossRef]

63. Zhou, K.; Zhang, J. Trade normalisation, export quality, and in-migration of skilled workers: Evidence from China. J. Econ. Behav. Organ. 2021, 184, 375-387. [CrossRef]

64. Agadjanian, V.; Gorina, E.; Menjívar, C. Economic Incorporation, Civil Inclusion, and Social Ties: Plans to Return Home among Central Asian Migrant Women in Moscow, Russia. Int. Migr. Rev. 2014, 48, 577-603. [CrossRef]

65. Carbone, J.T.; Mcmillin, S.E. Reconsidering Collective Efficacy: The Roles of Perceptions of Community and Strong Social Ties. City Community 2019, 18, 1068-1085. [CrossRef]

66. Wang, D.J. When do return migrants become entrepreneurs? The role of global social networks and institutional distance. Strateg. Entrep. J. 2020, 14, 125-148. [CrossRef]

67. Dimova, R.; Stephan, K. Inequality of opportunity and (unequal) opportunities in the youth labour market: How is the Arab world different? Int. Labour Rev. 2020, 159, 217-242. [CrossRef]

68. Aiyar, S.; Ebeke, C. Inequality of opportunity, inequality of income and economic growth. World Dev. 2020, 136, 105-115. [CrossRef]

69. Smith, J. Pay Growth, Fairness, and Job Satisfaction: Implications for Nominal and Real Wage Rigidity. Scand. J. Econ. 2015, 117, 852-877. [CrossRef]

70. Dietmar, F.; Hannes, R.; Stefan, T.; Xu, Y. Inequality, Fairness and Social Capital. Eur. Econ. Rev. 2020, $129,103566$.

71. Martino, S.; Prilleltensky, I. Happiness as fairness: The relationship between national life satisfaction and social justice in EU countries. J. Community Psychol. 2020, 48, 1997-2012. [CrossRef] [PubMed]

72. He, C.; Gober, P. Gendering Interprovincial Migration in China. Int. Migr. Rev. 2010, 37, 1220-1251. [CrossRef] 